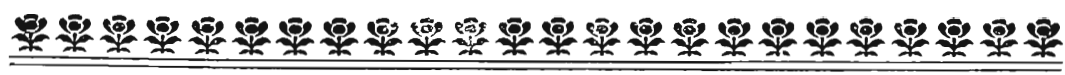

\section{CURSO DE DIREITO COMMERCIAL ${ }^{(1)}$}

\section{CAPITULO II}

Fontes do direito commercial brasileiro.

Evolução historica e importancia juridica dos usos e costumes.

Fonte, no sentido geral, é toda a causa geradora de um facto. Juridicamente, fonte é todo o orgão revelador do direito.

As fontes do direito commercial brasileiro podem ser classificadas em tres grupos:

a) fontes principaes

b) fontes secundarias

c) fontes scientificas

No corpo do nosso codigo commercial não se encontram disposições mencionando essas fontes.

O reg. 737, de 25 de Novembro de 1850, porem, preenchendo essa lacuna, declara no art. $2 .^{\circ}:$ "constituem fontes da legislação commercial o codigo do commercio $e$, subsidiariamente, os usos commerciaes $e$ as leis civis." $\mathrm{E}$ assignala que os usos commerciaes preferem ás leis civis, sómente nas questões sociaes e nos casos expressos no codigo.

(1) Vide esta Rerista, vol. 23, pag. 329. 
Essa disposição do citado reg. deve ser entendida de modo amplo, no sentido de comprehender todas as leis extravagantes de caracter mercantil que depois do codigo foram promulgadas.

Inspirado nos codigos francez, espanhol e portuguez, o nosso codigo, após uma elaboração de 17 annos, foi promulgado a 25 de Junho de 1850 , entrando em execução a $1 .^{\circ}$ de Janeiro de 1851.

Contem tres partes. uma geral, outra referente ao commercio maritimo e a terceira sobre quebras ou fallencias.

A estas tres partes foi incorporado o "Titulo Unico", que diz respeito á administração nas causas commerciaes e á organisação e competencia dos tribunaes do commercio.

O apparecimento do nosso codigo foi, positivamente, um acontecimento notavel na legislação americana, tanto mais quanto, em confronto com as fontes que o inspiraram, elle se revelou muito mais adiantado, sendo considerado uma codificação original.

Mezes após a sua promulgação, foi decretado o reg. 737 , de 25 de Novembro de 1850, reputado por todos os conhecedores do direito um monumento de sabedoria dos juristas daquelle tempo. E, forçoso é confessar, os nossos actuaes legisladores, ante a grandeza dessa obra, tiveram de conter o afan com que, desde o inicio da vida republicana, vêm manifestando na destruição, ás cégas, das leis do antigo regimen.

Em 1890, por decreto do governo provisorio, foi esse regulamento mandado applicar como processo civil em todo o territorio da Republica.

Graças a elle mesmo, o reg. 737 citado é ainda o nosso processo civil e commercial, como o é em quasi todos os Estados da Federação.

Convem observar que o codigo brasileiro, sem embargo do seu valor, para a época da sua promulgação, hoje, ante os progressos do trafico mercantil, notadamente na parte res- 
peitante aos transportes terrestre e maritimo, é deficientissimo.

Dahi, a razão de, nestes ultimos tempos, ser digno de notar a onda de leis visando o commercio, reduzindo os 912 artigos de que se compunha o codigo a setecentos e poucos actualmente em vigôr.

Com a doutrina firmada pela Constituição Fedłeral, segundo a qual á União compete legislar sobre o direito material e aos Estados sobre o direito processual, ficou tambem muito modificado o "Titulo Unico" do Codigo.

A despeito dos grandes inventos e melhoramentos visando a industria maritima, é certo que, nesse particular estamos na mesma situação em que nos encontravamos em 1850 !

A parte terceira sobre fallencias constituiu objecto das primeiras preoccupações dos legisladores republicanos, sendo a mesma revogada pelo dec. 917 , de 24 de Outubro de 1890.

Nos commentarios ao codigo commercial, de BENTo DE FARIA e ORLANDO, encontram-se quasi todas as leis e decretos que vêm alterando a nossa legislação mercantil, desde o Imperio.

O erudito commercialista patrio, CaRvalho DE MENDONÇA, no $2 .^{\circ}$ volume do seu Tratado de Direito Commercial Brasileiro, apresenta uma synopse da legislação commercial, posterior ao codigo, trabalho que põe o estudioso ao corrente de tudo o que existe, entre nós, sobre materia mercantil, sujeita á disciplina legal.

Conhecidas as fontes principaes do direito commercial, vejamos as subsidiarias, isto é, as leis civis e os usos mercantis.

Ao enunciar-se a ordem da invocação dessas fontes, surge esta pergunta: Que razões, que motivos levaram o 
nosso legislador a dar preferencia ás leis civis aos usos commerciaes, nas falhas do codigo?

Os juristas procuram explicar essa precedencia, na invocação das alludidas fontes, na influencia que sobre o codigo brasileiro tiveram os seus paradigmas e ás idéas dominantes ao tempo de sua elaboração, segundo as quaes 0 direito civil era a regra e o direito commercial uma excepção.

Sendo assim, justo era que, nos casos omissos do codigo, se mandasse recorrer á regra, isto é, ao direito civil.

Hoje, porem, que todos reconhecem ser 0 direito commercial moderno fructo das necessidades dos povos mercantis, como diz um escriptor, caracterisando-se pela sua unidade e cosmopolitismo, destinado a reger uma infinita variedade de factos economicos de natureza especial, nenhuma razão de ordem juridica milita em favor da theoria perfilhada pelo nosso codigo, mandando invocar as leis civis de preferencia aos usos commerciaes, como fontes secundarias do nosso direito commercial.

Por usos commerciaes devemos entender, com CARVALHO DE MENDONÇA, as normas ou regras observadas uniforme, publica e constantemente pelos commerciantes de uma praça e por estes considerados como juridicamente obrigatorios, para, na falta de lei, regularem determinados negocios.

Mas, essas, normas assim observadas pelos commerciantes devem reunir estes requisitos: a) ser geralmente seguidas pelos commerciantes de uma praça, de modo a formarem uma série de actos positivos; $b$ ) ser conformes á bôa fé e maximas commerciaes. Esta exigencia, como pondera Carvalho de MEndonça, inspirada no direito canonico, é perfeitamente dispensavel, por não ser licito suppôr que os commerciantes dêm direcção a certos actos, fundados em má fé́; $c$ ) não ser contrarias ás disposições do codigo ou da lei commercial posterior.

Este ultimo requisito afasta a possibilidade de permittir-se um uso contra a lei. 
Além dessas tres condições, o reg. n. ${ }^{\circ} 738$, de 25 de Novembro de 1850 , exigia que o uso tivesse mais de cincoenta annos.

Ora, essa exigencia não podia ser observada, como de facto não foi, por ser manifestamente contraria á natureza do uso, cuja energia está precisamente em revelação de uma regra, que deve ser applicada á uma relação juridica, não cogitada pela lei escripta.

No estado actual do nosso direito, a attribuição de collecionar os usos commerciaes, que reunam os requisitos acima apontados, pertence ás juntas commerciaes, nos termos do dec. de 19 de Julho de 1890.

Segundo 0 art. 30 desse dec., as juntas devem publicar nas folhas officiaes os usos de que tomaram assento, afim de sobre elles fazerem os interessados as observações que entenderem. Após tres mezes, é o uso proclamado regra obrigatoria para a relação juridica que o proviocou.

Pela legislação anterior, essa attribuição competia, a principio, aos Tribunaes de Commercio, e, posteriormente, ao Supremo Tribunal de Justiça. Tanto uns como o outro jamais se preoccuparam em executar esse encargo, como é sabido.

Como fontes do direito commercial, os usos podem ser geraes e locaes. Os primeiros, applicam-se em todo o territorio da Republica. Os segundos, são os adoptados em uma determinada praça commercial.

$\mathrm{Na}$ pratica dos negocios bem pode occorrer um conflicto entre um uso geral e outro local. Como resolver?

Contrariamente ao que se dá em direito civil, o uso commercial não tendo a sua autoridade bitolada pela sua maior esphera de acção, o que deve prevalecer é o uso local. 
Estudadas as fontes legaes, positivas do nosso direito commercial, passamos ao estudo das fontes scientificas, que alguns escriptores denominam complementares.

A lei escripta, fonte principal do direito positivo, por ser feita pelos homens, não pode ser inteiramente perfeita, isto é, não pode cogitar de todas as relações juridicas existentes ao tempo de sua elaboração, e, muito menos, das que a evolução social vai fazendo apparecer, as quaes, igualmente, devem ser disciplinadas, a bem da ordem juridica.

Para a solução dessas possiveis occorrencias, não previstas pelo legislador, o magistrado, o jurista, o interprete vão buscar elementos, subsidios nas fontes scientificas.

Essas fontes, consoante a lição dos escriptores, são: a analogia, a jurisprudencia dos tribunaes e o direito scientifico.

Do ponto de vista mais philosophico, a analogia é o processo logico segundo o qual o interprete applica aos casos não previstos pelo legislador as disposições que regem os casos semelhantes.

Este processus encontra-se concretisado na seguinte regra do direito romano _ "Ubi eadem causa, ibi idem jus statuendum"

Cumpre notar que a analogia, como fonte do direito, não deve fundar-se sómente na semelhança dos casos, como pretende VARRo, citado por SILVA CosTa, no seu "Direito Maritimo" Ella deve ter a sua razão de ser na identidade de motivos, na ratio legis.

No seu tão conhecido compendio "Encyclopedia de Direito", Roussel, estudando a analogia, como fonte do direito, diz que não se a deve confundir com a simples interpretação.

Pela analogia, diz o citado escriptor, o interprete faz o papel de legislador, substituindo-o; pela interpretação, o interprete só tem que apoderar-se do pensamento legisla- 
tivo, explicando-o, pelos processos formulados pela Hermeneutica.

$O$ poder judiciario, na applicação das leis aos casos concretos da vida social, por meio dos seus magistrados, exerce uma dupla funcção: a interpretativa, fixando o verdadeiro sentido da lei, para a sua justa applicação aos diversos casos occorrentes, e a suppletiva, completando as leis, quando estas forem deficientes.

No exercicio dessas duas funcções, os juizes e os tribunaes elaboram a jurisprudencia, que PICARD denominou especie de direito costumeiro.

E' sabido que a jurisprudencia não tem força de lei. Mas, pela autoridade doutrinal que lhe dá a nossa Constituição Federal, o poder judiciario pode tirar a força das leis, julgando-as inconstitucionaes.

CaRvalho de Mendonça, apreciando o valôr da jurisprudencia dos tribunaes, entre nós, diz: "é certo que na guarda e applicação da Constituição e das leis o poder judiciario intervem em especie e por provocação das partes interessadas; mas, o acto do poder legislativo julgado uma vez inconstitucional, ou do poder executivo considerado illegal, estão feridos de morte. Devem ser considerados peças inuteis na nossa legislação"

O direito, como observa IHERING, não sendo uma simples agglomeração de leis, o bom senso só não basta para comprehendel-o e applical-o ; á intenção juridica deve alliarse a educação juridica, para que o direito, como sciencia, seja consultado como fonte.

São orgãos do direito scientifico-os jurisconsultos, cujos trabalhos, cujos pareceres offerecem solução para. diversos casos complicadcs, não previstos pela lei. 
E' facto notado, dia a dia, invocarem os tribunaes, para reforço de suas decisões, as opiniões de notaveis jurisconsultos.

Cogliolo, na "Filosofia del Diritio Privato", com abundancia de considerações, põe em relevo a importancia que sempre tiveram, em todos os tempos, os jurisconsultos.

CicERo, em uma das suas magnificas orações, mostrando a supremacia do estudo da sciencia juridica entre os romanos, exclama: Roma querendo honrar com popular favôr os jurisconsultos cognominou-os sacerdotes justitix, e chamou a jurisprudencia sciencia das coisas divinas e humanas, e os seus cultores - oraculi totius civitatis.

\section{CAPITULO III}

Theoria dos actos de commercio. Caracteres, definiçóes e divisão de actos de commercio. Legislação brasileira.

Ante a variedade das formas por que se pode manifestar a actividade mercantil, os escriptores commercialistas e os codigos das nações mais cultas não conseguiram, até hoje, dar do acto de commercio uma noção inteiramente isenta de duvidas.

A historia do direito commercial, no longo periodo de sua formação, nos conta que, a principio, as relações commerciaes não tinham caracter proprio, no sentido de differençal-as dos actos da vida commum.

Mas, a expansão das transacções mercantis, os progressos das industrias e innovações introduzidas nos transportes terrestres e maritimos, induziram a creação de institutos, cuja applicação não podia mais ser regulada pelas regras severas do direito civil dos romanos. 
Por isso, ao lado desse direito que, por força dos acontecimentos, ficou estacionario, reduzido a compendio, como se diz, appareceram os usos e costumes, regulando essas relações novas, verdadeiros primordios da manifestação juridica do exercicio do commercio.

A autoridade desses usos e costumes levou, como já disse em outro capitulo, os commerciantes a organizar corporações de officios e misteres, com tribunaes proprios para 0 julgamento das questões que entre elles surgissem.

E essas leis, assim emanadas da acção corporativa, denominaram-se estatutos, que, se especialisando cada vez mais, formaram o direito dos mercadores, com o caracter de um verdadeiro jus singularis.

Nessa época, o acto de commercio era considerado

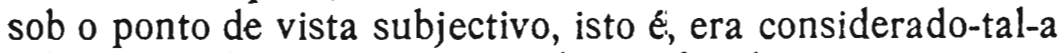
relação juridica sómente quando verificada entre commerciantes, no exercicio de sua profissão mercantil.

As descobertas da America e do caminho das Indias, porem, alargando de modo consideravel os negocios, provocaram, como era natural, a creação de um criterio objctivo, para a caracterisação do acto de commercio.

Formado esse criterio objectivo, real, positivo do acto de commercio, o direito commercial deixou então de ser um direito de classe, um jus singularis, para se tornar um direito especial, destinado a reger o commercio.

$\mathrm{Na}$ vigencia do direito estatutario, quando o direito commercial estava ainda na infancia, o criterio objectivo dos actos de commercio já era conhecido, mas só se tornou predominante com a publicação das celebres Ordenanças Francezas de Luiz XIV, de 1673, sobre commercio terrestre e de 1681 , sobre marinha.

Essa mudança do criterio subjectivo pelo objectivo é que determinou a controversia, ainda reinante entre os escriptores e os codigos, acerca da natureza do acto de commercio, sem embargo do gráo de adeantamento em que se encontra o direito commercial moderno. 
E' assim que o codigo francez de 1807, primeira legislação systematicamente organisada em materia mercantil, respeitando a tradição juridica e os principios proclamados pela Revolução de 1789 , estabeleceu regras reguladoras dos actos de commercio e definiu o commerciante.

Mas, o que é certo é que os legisladores francezes, seduzidos pelo direito estatutario, não tiveram coragem para definir o acto de commercio, fazendo tão somente uma enumeração dos actos com esse caracter, quando firmaram a competencia jurisdiccional do commercio.

Contemporaneamente, as legislações que disciplinam as relações civis e commerciaes por codigos differentes, não definem tambem o acto de commercio sob o ponto de vista scientifico-juridico.

$\mathrm{Na}$ doutrina, enorme é a divergencia entre os escriptores commercialistas, os quaes têm architectado grande variedade de construcções theoricas acerca do caracter do acto de commercio.

E' assim que, segundo uns, como MARGHIERI, PARDESSUS e MASSE', a caracteristica do acto de commmercio está na troca, porque dizem elles, o commercio é a troca.

Essa theoria, que é classica, não pode ser acceita, porque o commercio não se realiza somente pela troca, mas sim por outras fórmas de escambo.

Segundo outros, como Ruben DE Couder e BRAVARD, o que distingue o acto de commercio dos actos da vida civil é a especulação.

Tal conceito não é menos repugnante, pois, actos ha, nos quaes não se verifica nenhum intuito de especulação, que, no emtanto, são considerados commerciaes, como muitos outros existem, cuja realização obedece exclusivamente á intenção de especular, e são civis. 
Como exemplo, no primeiro caso, temos os acceites, saques e endossos nas letras de cambio, praticados por individuos não commerciantes, mas que a lei reputa, não obstante, commerciaes.

Como exemplo do segundo caso, podemos lembrar as grandes especulações sobre immoveis, que são actos civis, embóra praticados por commerciantes.

Na sua conhecida monographia "Actos de Commercio" MANARA, commercialista italiano, affirma ser a caracteristica do acto de commercio a mediação entre a producção e o consumo com o fito de lucro, para facilitar a circulação das riquezas.

Essa noção é fortemente criticada por VIVANTE, outro notavel professor italiano, o qual entende não ter MANARA feito mais que generalizar os caracteristicos da compra e venda, extendendo-os aos demais actos do commercio.

E' ainda Vivante que, tratando do acto de commercio, diz não ser possivel resumir num só concepto os differentes actos a que o legislador imprimiu o caracter mercantil. Pelo que, conclue, quem quizer informar-se no direito positivo, deve renunciar a uma definição inconciliavel com o direito vigente.

Lyón CAEn e RENAULt, notaveis commercialistas francezes, declaram por sua vez, sem hesitação, que o acto de commercio não encontra nas condições absolutas do direito e da justiça uma definição segura. E isto porque actos de commercio são todas as relações juridicas que, por motivos de utilidade pratica, o legislador subtraiu da acção do direito commum, para sujeital-os á disciplina de um direito especial. Onde, pois, o criterio para a determinação do acto commercial?

Entre nós, o notavel CaRvalHo de Mendonça, rompendo a timidez dos escriptores que têm versado o assumpto, partindo do facto de ser identico o conceito juridico e economico do commercio, considera actos de commercio todos aquelles pelos quaes se realiza a funcção do commer- 
cio. E procurando convencer, escreve o eminente commercialista: a industria mercantil tem por funcção distribuir o producto das outras industrias. Ella se interpõe entre productores e consumidores; suppõe a producção economica e procura servir o consumo. O seu fim objectivo é effectuar ou facilitar a troca dos bens, isto é, a circulação dos bens.

Essa explicação do eminente commercialista patrio justifica, não ha duvida, a definição que dá ao acto de commercio, do ponto de vista scientifico-economico.

Mas, ante o direito positivo, ella não pode ser acceita, porque é sabido que todos os codigos, cedendo ás exigencias juridico-sociaes, consideram commerciaes muitos actos nos quas não se encontram os elementos de mediação e de especulação.

No estado acual do direito, dois systemas diversos offerece a pratica legislativa para determinar a área da legislação mercantil.

Um, dá uma simples noção do acto de commercio, deixando aos tribunaes a faculdade de applical-a nos casos concretos.

Outro, menciona uma lista ou série de actos considerados commerciaes.

O primeiro systema é seguido pelo Codigo Hespanhol, cujo art. $1^{\circ}$ diz assim: "são reputados actos de commercio is comprehendidos neste codigo e outros de natureza inaloga"

O direito portuguez perfilhou esse systema, como se vê do art. $2 .^{\circ}$ do codigo commercial.

O segundo systema é adoptado pelos Codigos Francez, Chileno, Argentino, Italiano e lei belga de 1872. O Codigo Allemão, adoptando esse systema, restringiu-o, porem, estabelecendo uma lista taxativa dos actos commerciaes, tornando defeso aos tribunaes amplial-os por analogia. 
VIDARI, apreciando esse systema, o considera insustentavel, pela impossibilidade de encerrar-se em uma enumeração a multidão de actos commerciaes. E quem pretendesse, accrescenta o notavel commercialista italiano, encerrar em uma lista todos os actos mercantis, teria preoccupação igual á do menino, de que fala S. Agostinho, o qual tendo aberto um buraco na praia, por elle quizesse exgotar as aguas do mar.

Para nós, esses dois systemas não são acceitaveis pelos grandes inconvenientes que dão logar as interpretações extensivas dos tribunaes, o que sempre torna cahotica a jurisprudencia, pela falta de um criterio philosophico seguro que permitta conhecer, com exactidão, os actos que 0 legislador considera commerciaes e, por isso, distinctos dos actos civis.

O nosso Codigo Commercial não dá uma noção do acto de commercio, mas formula uma lista dos actos considerados commerciaes. Nesse ponto, afastou-se das fontes que o inspiraram - os velhos codigos francez, hespanhol e portuguez.

O reg. 737 , de 25 de Novembro de 1850, porem, menciona nos arts. 19 e 20 diversos actos considerados commerciaes em razão dos mesmos actos e das pessôas que os praticam e actos commerciaes em razão sómente das pessôas que os praticam.

Cumpre assignalar que a enumeração empirica dos actos de mercancia, estabelecida pelo art. 19 do citado reg., é meramente exemplificativa; e a que faz o art. 20 é taxativa, isto é, não pode ser ampliada por analogia.

\section{Classificação dos actos de commercio.}

Todos os escriptores francezes e italianos, inclusive os classicos, dividem, geralmente, os actos commerciaes em subjectivos e objectivos. 
A estas duas categorias de actos corresponde a classificação allemã - actos absolutos e relativos.

Actos objectivos do commercio são aquelles em os quaes desde logo se descobrem os elementos da commercialidade.

Actos subjectivos do commercio, tambem denominados, por alguns escriptores, relativos ou dependentes, são aquelles que, não contendo em si as caracteristicas do commercio, todavia entram para o dominio do direito commercial. Tanto vale dizer, são actos presumptivos do commercio, salvo prova em contrario. São commerciaes, por simples presumpção juris tantum.

VIDARI, o mais graduado representante da escola classica, manifesta-se francamente contrario á qualquer classificação dos actos de commercio. E a razão que apresenta está em que a distinç̧ão que se faz desses actos encontra-se sómente no proposito com que são praticados. Desde que uma relação juridica se dá para a exploração de um commercio, o acto é commercial; no caso contrario, o acto é civil.

Sem embargo dessa opinião, aliás autorizadissima, o certo é que todos os maiores escriptores da Italia seguem a classificação dos actos commerciaes em subjectivo e objectivos.

Mas, uma pergunta surge: essa classificação adapta-se ao systema da nossa legislação?

Pensamos que não.

Com effeito, o reg. 737 de 1850, tratando da jurisdição commercial, declara no art. 11: "não basta para determinar a competencia jurisdicional que ambas as partes ou alguma dellas sejam commerciantes, mas é essencial que a divida seja tambem commercial; outrosim, não basta que a divida seja commercial, mas é essencial que ambas ou uma das partes seja commerciante, salvo os casos e excepções do art. 20"

Essa disposição, como bem se vê, explica ou justifica a epigraphe do Cap. $3 .^{\circ}$ do reg. 737 de 1850 - "Da jurisdição commercial em razào das pessôas e dos actos" 
$\mathrm{O}$ acto de commercio, pois, no conceito do legislador brasileiro, deve conter os dois elementos - subjectivo e objectivo, isto é, pessôa commerciante e relação juridica commercial.

No Cap. IV do referido reg. 737, subordinado á epigraphe "Da jurisdição commercial em razão somente dos actos", encontra-se uma lista de actos reputados commerciaes em razão somente dos actos.

Consequentemente, os actos commerciaes, segundo o nosso direito, podem ser classificados em actos de commercio propriamente ditos e actos commerciaes por força de lei, actos que CARVAlHo DE Mendonça denomina artificialmente commerciaes.

Essa divisão estabelecida pelo reg. 737 está de accôrdo com os arts. 18 e 19, Titulo Unico, do Codigo Commercial.

Cumpre assignalar que a essa classificação de actos commerciaes, em subjectivos e objectivos, alguns escriptores francezes, como Thaller, Lyon CAEN e RENAUlt, ligam uma terceira classe de actos, que elles denominam mixtos, unilateraes, isto é, actos que são commerciaes para uma das partes contractantes e civis para a outra. Apresentam como typo desses actos a compra e venda de mercadorias para revendel-as, feita por um commerciante a uma pessôa não commerciante.

Ante essa theoria, no direito francez, muito se tem discutido sobre a jurisdição a que fica sujeito o não commerciante no caso apontado.

Segundo uns escriptores, a compra e venda nesse caso é um acto uno, indivisivel, integro, isto é, não pode ser scindido, para que uma das partes fique sujeita á jurisdição commercial, e a outra á civil.

Para outros commercialistas, sendo o direito commercial uma excepção ao direito civil, que é a regra, indiscutivel é que á jurisdição commum fique sujeita a parte commerciante. 
De resto, alguns escriptores entendem que ás partes é que cabe a escolha ou opção da jurisdição.

Vê-se, pois, que na doutrina franceza a questão não tem tido uma solução uniforme, tanto mais quanto o Codigo Commercial de 1807 não contem disposição alguma sobre o assumpto.

Devido á essa divergencia de opiniões, divergencia que se tem reflectido na jurisprudencia franceza, os codigos italiano, allemão, argentino e portuguez mencionaram em suas disposições a declaração expressa de que os actos unilateraes do commercio estão sujeitos á jurisdição commercial, salvo quando excluidos expressamente pelo legislador.

Essa theoria dos actos commerciaes mixtos foi, entre nós, acolhida sem reservas pelo acatado commercialista Silva Costa. Escrevendo um artigo, inserto no "Jornal do Commercio", do Rio de Janeiro, em 1903, sobre o assumpto, diz o seguinte: o não commerciante, que compra um objecto no estabelecimento commercial, pratica um acto civil-a compra-, regida pelo direito civil; e o commerciante, que vende esse objecto, pratica um acto mercantil-a venda respectiva. Si o não commerciante tem de accionar o commerciante em razão dessa compra e venda, tem de recorrer ao juizo do commercio; si o inverso se dá, tem o commerciante de recorrer ao juizo civel, em vista do art. 11 do reg. 737 , de 1850 .

No seu citado "Tratado de Direito Commercial", CARVALHO DE MENDONÇA refuta essa opinião de modo cabal. Segundo este commercialista, a interpretação do art. 11 do reg. 737 de 1850 deve ser feita de accôrdo com o art. 12 do mesmo reg., o seu complemento natural.

Não hesitamos em acompanhar CARvalho DE MENDONÇA nesse assumpto. 
Com effeito, o contracto de compra e venda, todos sabem, é uno e indivisivel. Quer dizer, não ha compra sem venda correspectiva. Um acto suppõe outro. Da alliança da compra com a venda é que resulta o respectivo contracto.

Para que a compra e venda seja commercial, é bastante que uma das partes seja commerciante, nos termos expressos e claros do art. 191 do nosso Codigo Commercial. Assim, um commerciante, comprando productos de um agricultor para os revender, a consequencia é ficar o não commerciante sujeito á jurisdição commercial, por se tratar de contracto puramente mercantil.

Dahi, a razão da regra do art. 12 do reg. 737 de 1850 , declarando ficar sujeita á jurisdição a parte não commerciante que contratar com commerciante.

Consequentemente, segundo o systema do nosso dirito positivo, a integridade do acto de commercio está fixada. Isto vale dizer que, entre nós, não existem actos simultaneamente civis e commerciaes.

Segundo a nossa legislação, os actos commerciaes podem ser classificados em dois grupos. natureza;

a) actos commerciaes propriamente ditos ou por

b) actos commerciaes por força da lei.

A estes dois grupos, Carvalho DE MEndonçA addiciona mais uma - a dos actos commerciaes por dependencia ou connexão.

Os actos do primeiro grupo encontram-se enumerados no art. 19 do reg. 737, de 1850.

Essa enumeração é meramente exemplificativa, isto o legislador, mencionando nesse artigo certos actos commerciaes, o faz, tendo em vista a circumstancia de serem os mesmos os mais frequentes na vida commercial. 
De sorte que, nos casos concretos, ao juiz compete verificar se o acto, de que se trata, está ou não nas condições de ser, por analogia, considerado commercial.

Si assim não fôra, como disciplinar essa enorme variedade de actos que a expansão commercial faz nascer dia a dia?

Cumpre ponderar que as operações indicadas no mesmo art. 19 do citado reg. 737 não são tratadas do mesmo modo. Para umas, o legislador contenta-se com um simples acto accidental de commercio. Para outras, porem, subordina a existencia do acto a facto de uma empreza.

O primeiro acto de commercio ou mercancia referido no art. 19 do reg. 737 é a compra e venda ou troca de effeitos moveis ou semoventes, para os vender (1) por grosso ou a retalho, na mesma especie ou manufacturados ou para alugar o seu uso.

Todos os escriptores, que analysam as disposições correlatas dos codigos estrangeiros, são accordes em affirmar ser a compra e venda o acto commercial por excellencia e o mais importante sob os pontos de vista historico, juridico e economico.

E tal conceito não escapou ao nosso legislador, pois, além de enumerar em primeiro logar esse contracto, o disciplinou em titulo especial, o $8 .^{\circ}$ do Codigo, por principios minuciosos, completos, como se vê dos arts. 191 usque 220.

Mas, tanto o art. 19 do reg., como o art. 191 do Codigo empregam a expressão-effeitos moveis- como sendo o objecto da compra e venda, quando éi certo que as fontes que os inspiraram não procederam assim.

Porque, então, preferiu o legislador essa expressãoeffeitos moveis-?

Essa preferencia só pode ser levada a conta da tradução mal feita da expressão franceza effects. Mas, o codigo francez quando trata do objecto da compra e venda refere-

(1) O legislador quiz dizer "revender". 
se ás denrées (productos alimentares) e marchandises (todas as coisas moveis) e não a effeitos.

Melhor seria se o nosso legislador redigisse o art. 19 n. 1 assim: "considera-se mercancia toda a acquisição a titulo oneroso para a revenda"

Quaes são, porem, as condições de que se deve revestir a compra e venda para ser considerada acto de commercio, segundo o nosso direito?

São estas:

a) ter por objecto coisas moveis,

b) ser o comprador ou o vendedor commerciante;

c) intenção do comprador de revender a coisa comprada ou de alugar o seu uso.

A primeira condição, pois, para que a compra e venda seja commercial é ser movel a coisa-seu objecto.

O nosso legislador excluiu, assim, os immoveis da commercialidade. Isto explica-se facilmente, porque, ao tempo em que o Codigo foi publicado, o conceito da circulação confundia-se com o simples transporte. E, para meIhor firmar a theoria de excluir os immoveis do commercio, o reg. 737, no art. 13, declarou peremptoriamente que as questões de bens de raiz, com excepção daquellas que occorrerem nas execuções ou derivarem de hypothecas commerciaes ou do direito da rescisão, não pertencem ao juizo commercial.

Andou bem o nosso legislador, excluindo, assim, de modo absoluto, os immoveis do commercio?

Os escriptores, que têm versado o assumpto, notadamente VIDARI, demonstram com argumentos irrefutaveis a improcedencia dessa theoria, uma vez que, do ponto de vista. economico, todos os bens, todos os valores são equiparados.

Tem-se argumentado, em justificativa da alludida theoria, que, sendo differente a natureza das coisas moveis da 
dos immoveis, determinando formalidades diversas para a transmissão de umas e outras, legitima é essa exclusão.

Não nos parece bem fundada essa razão. Que é que caracterisa o commercio? Respondem todos os escriptores, inclusive os partidarios da exclusão dos immoveis: - é o fito de lucro.

Sendo assim, insustentavel se nos affigura a doutrina que analysamos. De facto, o lucro tanto pode verificar-se nas negociações sobre moveis, como sobre immoveis.

Os economistas consideram, geralmente, os bens, as riquezas sob dois aspectos: o estatico, quando estudam os bens no seu valôr de uso, e o dinamico, no seu valôr de troca.

Assim, quando um individuo compra uma casa para sua moradia, especula, evidentemente, sobre o seu valôr de uso, e, neste caso, o acto é civil. Mas, se o mesmo individuo compra a casa para a revender, indiscutivel é que pratica um acto commercial.

$\mathrm{Na}$ doutrina dos escriptores encontram-se duas objecções disparatadas contra a commercialidade dos immoveis.

A primeira consiste no seguinte: os immoveis, não se prestando á deslocação, exigida no commercio, não podem, por isso, constituir o seu objecto.

Essa objeç̧ão, porem, não tem importancia e a sua acceitação importaria em desconhecer o concepto economico e juridico do commercio, e sua confusão com a industria de transporte.

Com effeito, ninguem jamais affirmou prestassem os immoveis á deslocação material. Mas, sustentar que essa deslocação é necessaria para a existencia do commercio, é um desproposito. Facil é a demonstração desse asserto. A circulação, como movimento geral dos valôres, pode, economicamente, dar-se independentemente da deslocação material desses mesmos valôres, pela simples transferencia por endosso dos titulos representativos desses valôres, como se 
faz com as mercadorias depositadas nos armazens geraes. Em capitulo especial trataremos desse assumpto.

A segunda objecção não é menos sediça que a primeira. Consiste nisso . pela natureza e importancia da propriedade immobiliaria, a lei tem necessidade de estabelecer certas formalidades para a sua transferencia.

$\mathrm{O}$ excesso de formalismo para a transferencia dos immoveis não justifica a segunda objecção levantada contra a commercialidade desses bens.

De facto, pelo nosso direito actual, as sociedades anonymas, qualquer que seja a natureza de suas operações, sobre moveis ou immoveis, são sempre regidas pela lei commercial.

De resto, essa questão só tem hoje valôr historico, pois, em muitos codigos, como o portuguez, o rumaico e o italiano, encontram-se disposições expressas permittindo a commercialidade dos immoveis.

A segunda condição da compra e venda é ser commerciante o vendedor ou o compradior. Essa exigencia está firmada pelos arts. 191 do Codigo e 10 e 11 do reg. 737, de 1850.

A terceira condição é a intenção de revender na occasião da compra.

Mas, como verificar esse intuito, por parte do comprador? Como concluir desse acto - a compra, a intenção de revender?

E' essa, como se vê, desde logo, uma pura questão de facto, que os juizes devem resolver conforme as circumstancias.

Assim, essa intenção pode resultar de forma dada ao contracto, da quantidade e qualidade das mercadorias, e outros factos indicativos de que a compra foi feita com o intuito de especulação. 
Mas, tem-se perguntado: se o commerciante, que comprou a mercadoria com o intuito de revendel-a, mudar depois de resolução, pratica acto de commercio?

A resposta não pode deixar de ser affirmativa. Desde que o commerciante comprou para revender, qualquer resolução em contrario, tomada posteriormente, não terá influencia para modificar o acto commercial, que continúa a subsistir. O commerciante que compra mercadorias com o fito de especular sobre a sua revenda, ainda mesmo que não lucre, isto é, que tenha prejuizo com essa revenda, 0 . acto é commercial. O que a lei quer é que a especulação exista no momento da acquisição da mercadoria. Contrariamente, um commerciante, comprando objectos para seu uso particular, e depois mudando de resolução, revendendoos, não pratica acto de commercio.

Do que vem dito, segue-se: não é commercial a compra de mercadorias para o exercicio de uma profissão não commercial, ainda que tenham de ser revendidas como accessorios de coisas não compradas. LYON CAEN e RENAULT dão, desse caso, o seguinte exemplo o vinhateiro compra toneis para acondicionamento dos seus productos; revendendo esses toneis, com o vinho, não pratica acto de commercio, porque essa revenda é um accessorio da venda do vinho, que é acto civil.

A compra de coisas moveis para alugar o seu uso é tão commercial, como a compra para revendel-as. Os principios applicaveis a um e outro sâo os mesmos.

Operações de cambio, de banco e corretagem (n. 2 do art. 19 do reg. 737 de 1850)

As operações de cambio dividem-se em duas classes, segundo a opinião geralmente seguida pelos escriptores: cambio manual ou miudo, que consiste na troca de moedas metallicas ou de papel moeda, nacionaes ou estrangeiras por 
outras moedas, em determinada praça; e cambio trajecticio ou mercantil, que tem por objectivo proporcionar dinheiro a uma pessoa em logar differente do contracto.

Essa especie de cambio age por meio da letra de cambio, que é o instrumento do contracto de cambio, segundo o qual uma pessôa se obriga, em um logar, para com outra a fornecer-lhe, em outro logar ou praça, essa quantia recebida.

O cambio manual é contemporaneo da moeda. Lógo que esta appareceu, surgiu aquelle, aliás muito praticado entre os antigos povos, como os gregos e os romanos.

Mas, qual a razão dessa classe de cambio?

$\mathrm{O}$ que determinou o seu apparecimento?

Todos reconhecem que foi devido á diversidade de padrões monetarios, que se instituiu a troca de dinheiros ou moedas. Sendo assim, parece que não havia necessidade do nosso legislador estabelecer a disposição especial do $n .^{\circ} 2$ do art. 19 do reg. 737, quanto ás operações de cambio, por estarem as mesmas virtualmente comprehendidas no n. ${ }^{\circ} 1$ do cit. art. (do reg. 737)

Tanto é procedente essa observação, quanto é certo que o Codigo Commercial, tratando da compra e venda, declara expressamente, no art. 191, que na classe dos moveis deve comprehender-se a moeda metallica e o papel moeda.

O cambio mercantil, como facilmente se percebe, evitando os perigos e despezas com o transporte do dinheirn, veiu facilitar, e muito, as transacções commerciaes entre individuos de praças differentes.

Analysando essa disposição do reg. 737, Carvalho DE MEndonçA entende que, ante o uso generalisado das letras de cambio e notas promissorias, tanto nas relações da vida civil, como na commercial, e dada a fórma especial de que se revestem esses titulos, pela lei n. ${ }^{\circ} 2.044$, de 31 de Dezembro de 1908, as operações dessa especie de cambio devem passar para a categoria dos actos de commercio por 
força de lei, afim de não fraccionar a materia do direito cambial.

Operações de banco. - Modernamente, não se limitam os bancos, como nos primeiros tempos, á simples troca de numerario. Hoje, especulam sobre fundos publicos, sobre emprezas industriaes, sobre depositos, cauções, descontos, etc.

Todas as operações bancarias são inilludivelmente commerciaes, porque em todas ellas se descobre a especulação, o fito de lucro.

A corretagem, segundo BÉDARRIDE, é a especulação pela qual um individuo, constituindo-se intermediario assalariado, entre pessôas com interesses distinctos, recebe as propostas de uma e as transmitte á outra, e, ajustado o negocio, põe ambas em relação.

Segundo a opinião de todos os escriptores, a corretagem é um dos mais energicos auxiliares das transaccões commerciaes e um acto de commercio por virtude propria.

A corretagem, embora tenha grande affinidade com a commissão, todavia com esta não se confunde. Com effeito, o corretor, agindo como intermediario nas operações, figura ostensivamente em nome de outrem; ao passo que 0 commissario, estipulando para outrem, o faz em nome proprio, figurando apparentemente como interessado directo.

Mas, se consoante o systema da nossa legislação (art. 191 do Cod. Commercial e art. 11 do feg. 737) o acto de commercio propriamente dito ou por natureza depende da qualidade de commerciante de quem o pratica, e não sendo o corretor commerciante, sem embargo de algumas opiniões em contrario, segue-se que melhor ficaria a corretagem na lista dos actos commerciaes por força de lei, a que se refere 0 art. 20 do reg. 737 
Emprezas de fabricas, de commissões, de depositos, de expedição, consignação $e$ transporte de mercadorias, de espectaculos publicos.

As operações dessas emprezas são tambem consideradas commerciaes pelo n. 3 do art. 19 do citado reg. 737

Segundo os nossos vocabulistas, a expressão empreza significa o conjuncto de individuos que formam ou dirigem uma associação mercantil ou industrial.

Entende Manara que empreza é a reunião e direcção de forças productivas - nâtureza, capital e trabalho - para um fim determinado.

Para nós, empreza é a pluralidade de acíos frequentes, relacionados com o commercio, constituindo uma profissão.

Dessa definição resulta que a empreza não exige pluralidade de pessôas, mas sim de actos ou operações, pouco importando a circumstancia de pertencer a uma ou a varias pessôas. Não ha duvida que as emprezas, na maioria dos casos, necessitam do auxilio de varias pessôas, mas esse facto não é que dá o caracter de empreza.

Isto quer dizer que pode existir empreza quando um só individuo entrega-se a actos repetidos, indicando uma profissão.

As emprezas podem ser exercidas por pessôas singulares ou por sociedades. E, conforme o seu objectivo, podem ser commerciaes ou civis.

Emprezas de fabrica. - A expressão fabrica comprehende todas as operações que têm por fim transformar as materias primas em mercadorias aptas para o consumo.

O fabricante pode proceder de dois modos: comprando materia prima para revendel-a, depois de transformada ou manufacturada em outra mercadoria, ou recebendo materia prima ou mercadoria para modifical-a, aperfeiçoal-a. 
No primeiro caso, o acto do fabricante incide no n. 1 do art. 19 do reg. 737 No segundo caso, embóra não se ajuste ao citado n. ${ }^{\circ}$ e art. do reg., é acto commercial, porque o fabricante especula sobre a differença entre o preço do uso dos machinismos, salarios de operarios, etc. e o que cotra pela fabricação.

Alguns escriptores, como NoGUIER, por ex., distinguem o fabricante do simples artista. Assim diz elle: o artista loca o seu serviço, o seu trabalho, que é feito sob as ordens do patrão, não compra materia prima para revendela; trabalha para viver. O fabricante, ao contrario, é o especulador que trabalha para enriquecer.

Emprezas de commissões. - A commissão, segundo os arts. 165 e 166 do Cod. Commercial, é a gestão de negocios mercantis de terceiros e em nome do commissario.

Distingue-se a commissão do mandato em que, neste, o mandarario age em nome e por conta do mandante, e na commissão, o commissario, agindo em nome proprio, o faz, todavia, por conta do committente.

Essa distincção, cumpre assignalar, não se encontra no direito francez.

Emprezas de deposito. - Comprehendem os armazens de deposito, trapiches e armazens geraes. As operações dos dois primeiros armazens não têm importancia, porque o seu destino está exclusivamente na guarda e conservação de mercadorias, destinadas ao commercio.

Os armazens geraes, porem, têm grande importancia, pois, prestam enormes serviços, eis que além de se destinarem á guarda de mercadorias, podem emittir titulos representativos dessas mercadorias, os quaes, pelo endosso, podem ser objecto de diversas negociações commerciaes.

Emprezas de transporte. - O transporte, hodiernamente, com o aperfeiçoamento dos meios de conducção, terrestre e maritimo, é, positivamente, um elemento de producção, porque valoriza as mercadorias, collocando-as ao alcance dos consumidores. 
O transporte, embóra possa ser explorado por pessôas singulares, todavia é certo que, em regra, as grandes emprezas são exploradas por sociedades anonymas, maximé tratando-se de emprezas que exigem grandes capitaes para a sua constituição.

Emprezas theatraes. - Por emprezas dessa natureza deve-se entender não só os estabelecimentos theatraes, como aquelles que têm por fim recrear e divertir o publico, mediante uma remuneração, como cinemas, circos, hyppodromo, etc.

Dahi, o dizer-se que o emprezario tanto pode exercitar as suas operações em casas fechadas, como ao ar livre.

Os escriptores suscitam esta questão: os contractos entre o emprezario e os autores, musicos, organizadores da mise en scene etc. são commerciaes? Ou melhor ainda: tudo aquillo que a empreza adquire para a composição do espectaculo é commercial?

A jurisprudencia franceza tem firmado que os contractos feitos entre essas pessôas nada têm de commerciaes. O artista, contractando com o emprezario, compromette-se a exhibir em publico os seus talentos artisticos, no drama, no lyrico, na opereta, etc. Esse acto é pura locação de serviços, de natureza civil, perdendo, porem, esse caracter, e tornando-se commercial, quando o artista participa dos lucros da empreza.

Essa doutrina foi acceita por Carvalho DE MENDONÇA.

Não nos parece, porem, bem fundada essa opinião. $\mathrm{O}$ actor, contractando o seu serviço, colloca-se na mesma posição de um jornalista, de um escriptor diante do seu editor. $\mathrm{O}$ argumento invocado de que o concurso dos actores é indispensavel para a existencia das emprezas theatraes, prova demais. De facto, o concurso de operarios, de contramestres tambem é indispensavel ao fabricante, e, no emtanto, ninguem affirma que elles se compromettem commercialmente. 
De resto, para a existencia da empreza theatral, não ha necessidade do concurso de um conjuncto de artistas, pois, para que se verifique uma empreza, basta, como já vimos, a simples reiteração de actos commerciaes, praticados por uma só pessôa. Diversas emprezas theatraes, como as dos celebres transformistas FREGOLI e ALDO, eram constituidas desses actores e seus bonecos.

Actos commerciaes por força de lei.

O fundamento legal dessa classe de actos commerciaes encontra-se no art. 20 do reg. 737, com esta epigraphe: "E a jurisdição commercial em razão dos actos sómente"

Os actos enumerados por esse art. são reputados commerciaes por méra utilidade pratica. Na maioria delles, não se descobrem os elementos de commercialidade. Pouco importa que aquelle que os pratica seja commerciante ou não. São commerciaes porque assim o entendeu o legislador, e nada mais.

O eminente Berlay, estudando essa categoria de actos, insurge-se contra ella, e affirma serem commerciaes taes actos por abuso das leis.

O commercialista patrio Carvalho de MendonçA, no seu tantas vezes citado "Tratado de Direito Commercial", justificando o procedimento do nosso legislador, considerando commerciaes os actos referidos pelo art. 20 do reg. 737, diz serem duas as ordens de razões que amparam a doutrina da nossa legislação. A primeira está em que, quando foi promulgado o Codigo Commercial, as nossas leis civis eram muito deficientes, sinão cahoticas. Dahi, a necessidade de se sujeitar ao direito commercial certos institutos, como a locação de serviços e de coisas. A segunda encontra-se na maior garantia e rapidez que offerece a legislação mercantil para a solução das controversias forenses. 
Sem pretendermos discutir essas razões, o certo é que, hoje, nada justifica essa violencia do legislador, sujeitando á lei commercial actos que são, substancialmente, civis.

Ao analysarmos esses actos, surge, para logo, essa pergunta , a enumeração que delles faz o art. 20 do reg. 737 é taxativa ou exemplificativa?

Sendo uma derogação dos principios juridicos e economicos que governam os actos commerciaes, a enumeração alludida não pode deixar de ser considerada taxativa, não podendo, pois, ser ampliada por analogia. Sob qualquer pretexto não podem os actos enumerados no art. 20 ser regulados pelo direito civil, ainda que se prove que nenhuma relação tenham com o trafico mercantil.

$\mathrm{O}$ n. ${ }^{\circ} 1$ do art. 20 do reg. 737 declara commerciaes as questões entre particulares sobre titulos da divida publica e outros quaesquer papeis de credito do Governo.

Consoante o nosso systema politico, as dividas publicas podem ser federaes, estaduaes e municipaes. Todas ellas estão incluidas nesse numero do art. 20.

Confrontando, porem, esse dispositivo com o que diz o art. 19 do Codigo Commercial, uma antinomia surge desde logo. Com effeito, segundo esse art. do Codigo Commercial, é unicamente considerada mercantil a compra e venda de effeitos moveis, titulos de fundos publicos e papeis de credito do Governo, comtanto que seja commerciante o vendedor ou o comprador. Ora, se pelo n. ${ }^{\circ} 1$ do art. 20 do reg. 737 citado, as transacções sobre taes titulos são commerciaes por força de lei, embóra não intervenha nellas commerciante, é clara, é manifesta a antinomia entre as duas disposições.

No n. ${ }^{\circ} 2$ do cit. art. 20 do reg. 737 , o legislador declara commerciaes as questões referentes ás companhias e sociedades, qualquer que seja a sua natureza e objecto.

Ante os termos genericos dessa disposição, tem-se discutido se nella €stão comprehendidas as questões relativas ás sociedades civis. 
Para pôr termo ás duvidas que no regimen imperial foram levantadas, o ConsElHEIRO NABUCO, em 1855, então Ministro da Justiça, expediu o aviso de 21 de Agosto, no qual declarou não haver razão para essas duvidas, pois, 0 art. 19 do Titulo Unico do Cod. Commercial e o art. 20 n. 2 do reg. 737 se referiam sómente ás sociedades commerciaes. De sorte que as sociedades constituidas por motivos religiosos, literarios, scientificos, etc. estão sujeitas á legislação civil.

O Supremo Tribunal do Imperio adoptou a doutrina desse Aviso, como se vê em um Accordão de Julho de 1862. O DR. Dino Bueno, que por muitos annos foi professor emerito da nossa Faculdade e seu director, em artigo publicado na revista "O Direito", sustentou tambem a mesma opinião. CARVALHo DE MENDONÇA, por sua vez, entende que 0 n. 2 do cit. art. do reg. 737 somente se refere ás sociedades commerciaes.

Não estamos de accôrdo com essa solução, que reputamos arbitraria. E' regra de hermeneutica que onde a lei não distingue, não é licito ao interprete distinguir. $O$ que diz o art. 20 no seu n. ${ }^{\circ} 2$ ? Isto: serão tambem julgadas em conformidade das disposições do Codigo as questões de companhias e sociedades, qualquer que seja a sua natureza e objecto" Esse dispositivo é reproducção do art. 19 \2 do Titulo Unico, do Codigo.

Ora, se esses arts. falam tão claramente em sociedades de qualquer natureza ou objectivo, como pretender restringil-as ás sociedades commerciaes? O Aviso alludido não pode revogar a lei. Elle vale somente pela autoridade moral e juridica do Ministro que o expediu.

Os julgados dos tribunaes não são tão numerosos que permittam a supposição de uma jurisprudencia firmada sobre o assumpto. E se jurisprudencia houvesse, seria corruptela, pela sua manifesta opposição á lei.

$A$ locação de coisas tambem é reputada commercial pelo n. 3 do cit. art. 20 do reg. 737. 
A locação, a que se refere esta disposição, é que tem prazo determinado e preço certo. A locação de serviços, que tambem tem prazo determinado e preço certo, é acto commercial por força de lei.

As operações sobre letras de cambio e notas promissorias são da competencia do juizo commercial, assim como as referentes a seguros, riscos e fretamentos.

Como já assignalamos, a estas duas classes de actos commerciaes, CARvalHo DE MEndonça ajunta uma terceira, a dos actos commerciaes por dependencia ou connexão.

Sobre essa classificação, escrevemos uma dissertação para o concurso, a que nos sujeitamos, em 1897, para o logar de lente substituto da então $6 .^{a}$ secção da nossa Faculdade de Direito, com a epigraphe seguinte:

"A theoria chamada do accessorio, que determina a commercialidade dum acto em razão da sua connexão com o exercicio do commercio, não se adapta ao systema da lei patria"

"E' facto notado por quasi todos os modernos commercialistas a tendencia, dia a dia maior, da jurisprudencia para ampliar o dominio da lei commercial e a jurisdição dos tribunaes do commercio; e de tal modo que bem pode vir a succeder que o direito considerado de excepção, avassalando, progressivamente, coisas, factos e pessôas, anties sujeitas á lei e ao juizo commum, breve alcance inverter sua posição ante o direito civil.

Quasi tudo é mercancia, quasi tódos são mercadores ou sujeitos á jurisdicão commercial, tal o objectivo da actual jurisprudencia.

Não nos faremos cargo de discutir se essa tendencia corresponde a necessidades reaes e reclamos inilludiveis de ordem economica entre os povos civilizados: attrahido pela novidade $ะ$ pelo interesse pratico do assumpto, não mais 
pretendemos que sujeitar á censura dos doutos os motivos de ordem juridica em que se funda o enunciado na epigraphe deste trabalho, relativamente á theoria do accessorio - uma das mais accentuadas manifestações da jurisprudencia avassaladora a que, de começo, alludimos.

$O$ commerciante pratica actos que, não constituindo 0 exercicio do seu commercio, com este são, todavia, intimamente connexos: compra innumeros objectos sem a intenção de os revender, mas com méro intuito de os utilizar na sua exploração profissional - vehiculos para o transporte de mercadorias, livros para a sua escripta, balcões e utensilios. varios para o seu armazem, etc.

Taes actos não são commerciaes de si mesmos, faltamlhes os requisitos essenciaes da mediação e especulação; podem, entretanto, ser reputados mercantis em razão da sua dependencia com o commercio de quem os pratica.

Tal a summa da theoria, modernamente ensinada por alguns escriptores e não raro applicada por tribunaes superiores, principalmente na França e na Italia.

Em justificação dessa theoria, sob o ponto de vista doutrinario, tem-se alludido ao principio de direito - accessio cedat principali — de tão fecundas e variadas applicações ás relações quer civis, quer commerciaes; assim como sob o aspecto da lei positiva, têm os commercialistas francezes e italianos pretendido autorizar a nova classe de actos commerciaes por accessão com a disposição do art. 638 do Cod. Commercial Francez, reproduzido no moderno Cod. Italiano, art. $4 .^{\circ}$, em virtude do qual presumem-se commerciaes os contractos e obrigações dos commerciantes, quando não sejam essencialmente civis, ou a sua não commercialidade não resulte do proprio acto.

Lyon CaEn \& Renault (Traité, tomo I, n. ${ }^{\circ} 171$, nota I), os mais esforçados dentre os propugnadores da theoria, vão mesmo até ao ponto de a reputarem acolhida e sagrada por todos os novos codigos europeus, citando os. 
Cods. allemão, art. 273, hungaro, art. 260, lei belga de 1872 , art. $2 .^{\circ}$, ult. al. e italiano, art. $4 .^{\circ}$

Entretanto, á simples leitura das disposições citadas, vê-se que nenhum desses codigos expressamente inclúe uma nova classe de actos reputados commerciaes, a titulo de accessorios, como o francez, e apenas melhorado o respectivo enunciado literal, referem-se á classe de actos presumptivamente commerciaes, em razão da qualidade de commerciante de quem os pratica.

Veremos pouco adiante que nenhuma co-relação existe entre as mencionadas duas classes de actos e quão falsa é a genealogia que se pretende estabelecer, remontando-se da segunda á primeira dessas classes.

Antes de investigarmos os fundamentos da theoria, cumpre-nos expôr qual a amplitude da sua applicação, ponto esse sobre o qual os jurisconsultos, que a sustentam. ainda não se acham de accôrdo.

$\mathrm{Na}$ jurisprudencia constituem casos julgados, dentré muitos, os seguintes, referidos por LYON CAEN \& RENAUL (loco cit.), nos quaes a commercialidade decorre da relação de dependencia dum acto com o exercicio duma mercancia :

a) os contractos pelos quaes um commerciante convenciona com architectos, empreiteiros ou operarios reparações em seus armazens;

b) a compra ou a locação de utensilios necessarios para o serviço dum estabelecimento commercial, compra de vehiculos, de machina ou instrumento para uma fabrica,

c) os contractos relativos á locação de serviços de prepostos, caixeiros e outros empregados em estabelecimentos commerciaes, 
d) o contracto de mandato conferido por commerciante para cobrança de creditos provenientes do seu commercio (1) ;

e) o contracto de seguro contra incendio, feito por commerciante e relativo aos moveis do seu armazem ou ao immovel em que tem o seu estabelecimento;

f) a compra ou a venda dum fundo de commercio.

Muitos outros julgados, inspirados na referida theoria, encontram-se em MASSÉ, RUBEN DE CóUDER e outros sobre especies semelhantes.

Entretanto, quer a jurisprudencia dos tribunaes, quer a doutrina dos commercialistas, muito divergem sobre a applicação da theoria.

Assim é que pretendem, os que a fazem derivar das disposições dos arts. 631 e 632 do Cod. Commercial francez, que ambas as partes sejam commerciantes de conformidade com o texto legal - Toutes les obligations entre négociants, marchants et banquiers; ao passo que os que pretendem fundal-a no art. 638 do mesmo Cod., dispensam esse requisito, applicando-a mesmo ao caso em que o acto é praticado por pessôa ainda não investida da qualidade de commerciante, comtanto que se relacione com o commercio que essa pessôa projecta emprehender (LYON CAEN \& RENAULT, op. cit. n. ${ }^{\circ} 174$ )

Assim creada uma nova classe de actos intencionalmente commerciaes, aos illustres professores da Faculdade de Direito de Paris não foi difficil dar um passo adeante, ampliando a theoria do accessorio ás operações connexas a actos isolados de commercio, ainda que praticados por pessôas não commerciantes.

Eis como os autores pretendem justificar essa ousada innovação:

"La theorie de l'accessoire n'est communement admise que pour les actes d'un commerçant. Ne convient -il pas

(1) Sobre esse caso não é uniforme a jurisprudencia franceza, como aliás reconhecem $Z$. Caen \& Renault (pag. 150 do vol I, op. cit). 
de l'entendre d'une manière plus large, en l'admettant pour toutes les opérations se rattachant à un acte isolé de commerce fait par un commerçant? Ainsi, un individu, que n'est pas commerçant de profession, fait une operation commerciale; il achète, pour exemple, une coupe de bois pour la revendre; pour l'execution de cette opération, il fait divers contrats, il traite avec des ouvriers pour l'abatage des arbres, avec des vouturiers pour les transporter, etc. Ne serait-il pas raisonable de dire que ces contrats ont le caractère du contrat principal auquel ils se rattachent, que le même esprit de espéculation commerciale les a inspirés? Celà se comprendrait en legislation, celà est-il trop hardi en l'absence de texte? Nous ne le pensons pas. L'art. 91 C. Com. considère bien comme un acte de commerce le contrat de gage, par cela seul qu'il est conclu à l'occasion d'une dette commerciale. C'est, il est vrai, une disposition qui n'a été introduite dans nos lois qu'en 1863, mais il faut remarquer que sur ce point l'art. 91 ne semble nullement édicter un régle particulière. En indiquant le cas dans lequel le găge doit être consideré comme commercial, il applique une régle dont il suppose l'éxistence" (n. 174 bis)

No extracto supra, que de industria transcrevemos do original, já claramente se percebem as vacillações da doutrina sobre o fundamento legal da theoria do accessorio.

Já não se a filia, como se vê, ás disposições dos arts. 631,632 e 638 do Cod. Comm. francez; a razão que a justifica é de ordem mais elevada. - é a theoria dos contractos principaes e accessorios.

Cumpre, porem, ainda notar que a theoria dos contractos não é base sufficientemente larga para a magnitude que se tem dado á casuistica do accessorio. Tanto a jurisprudencia franceza, como os commercialistas citados, affirmam resolutamente que os quasi-contractos, os delictos e quasi-delictos relativos ao exercicio dum commercio de- 
vem ser considerados commerciaes em virtude da regra sobre o accessorio, (1)

Assim expostos os fundamentos e as applicações da theoria, podemos analysal-as em face dos principics de direito de que se soccorre, bem como confrontal-a com o systema da lei patria.

Como se vê do que temos expendido, na ultima phase do seu desenvolvimento transcende a theoria do accessorio dos limites dos arts. 631, 632 e 638 do Cod. Comm. francez e das disposições correlatas dos cods. estrangeiros mais recentes: a commercialidade dos actos não é méra presumpção juris tantum (admitrindo prova em contrario) baseada na qualidade de commerciante da pessôa que os pratica, essa qualificação tanto pode ser attribuida ás operações referentes ao exercicio da industria mercantil, considerada como profissão habitual, como ás que apenas se relacionam a actos de commercio isolados de pessôa não commerciante.

Destarte, o fundamento juridico-philosophico dessa theoria vem a ser o principio da subordinação do accessorio ao principal.

E' sob esse aspecto que, em primeiro logar, devemos sujeital-a á nossa censura.

Temeridade, embóra, da nossa incomipetencia ante a reconhecida autoridade dos commercialistas que applicam 0 alludido principio a essa singular transposição de actos civis em commerciaes, não duvidamos, entretanto, affirmar que essa applicação procede de falso concepto das noções fundamentaes da sciencia juridica.

A razão philosophica em virtude da qual a união duma coisa a outra constitue, desde o Direito Romano, uma causa de acquisição ou da determinação da natureza juridica do accessorio, consiste na inseparabilidade de facto ou de di-

(1) L. Caen \& Renault, op. cit. n. 180; Pandectes Belges, verbe acte de commerce, no 759 e seguintes. 
reito de ambas, salvo os casos particulares em que a utilidade publica justifica a união que, de facto, seria possivel fazer cessar.

A lição dos commentadores do Direito Romano, dentre os quaes basta-nos citar MUHLENBRUCH (Doctrina Pandectarum, $\S 123$, pg. 205, e ORTOLAN (Explication des Institutes, ad. liv. II, tit. I, pag. 365) põe na maior evidencia não só o fundamento como tambem os limites da regra accessio cedat principali.

"Si une chose, diz OrTOLAN, vient reunir, s'attacher á la mienne, non par simple rapprochement, par simple adherence qui laisserait á chacune son individualité; mais s'incorporant, s'identifiant avec elle de manière à ne plus en faire qu'une dépendence, qu'une partie subornée, il y a là un fait puissant, qui ne saurait être sans influence sur le droit, et qui devra, bien souvent, commander impérieusement"

E' o que mais concisamente já havia enunciado o jurisconsulto PAUlo, no Digesto, VII, fgr. 23 \3.." “...necesse est, ei rei cedere id, quod sine illa esse non podest"

Que sob o mesmo fundamento e condições foi o principio acolhido no direito moderno, vê-se em MourLon (Rep. ecrit. sur le Cod. Nap. nos, 1441 e seguintes), AUBRY ET RAU (Cours de Droit Civil Français, tom. IV, \304).

Ora, sendo a inseparabilidade, ou pelo menos o interesse publico a razão da subordinação juridica do accessorio ao principal, inapplicavel é o principio a coisas ou a relações de direito, substancialmente differençadas por caracteres especificos que as individualisam. E' o que occorre com referencia á distinç̧ão entre os actos civis e commerciaes, fundamento de duas ordens de relações juridicas, que constituem o objecto de dois ramos differentes do direito privado e determinam a creação de duas jurisdições diversas.

Os actos commerciaes distinguem-se dos civis por caracteres de natureza economica, do que decorre a necessidade de classifical-os separadamente e subordinal-os a regras juridicas adequadas á natureza especial daquelles actos. 
A simples connexão accidental dum acto, em que faltam os requisitos da commercialidade, com uma operação mercantil, não pode juridicamente determinar a sujeição daquelle ás leis e á competencia jurisdicional, que regem a industria do commercio: a inseparabilidade não existe, nem a utilidade se impõe.

E' verdade que a lei commercial, em quasi todos os paizes cultos, tem subordinado ao seu dominio industrias e serviços, méramente auxiliares do commercio, isto é, que não constituem uma mediação, exercida com o animus lucrandi, entre a producção e o consumo, taes como as emprezas de commissão, de deposito, de expedição, de consignação, de transporte de mercadorias, etc. (art. $19 \S 3 .^{\circ}$ do reg. 737 de 25 de Novembro de 1850)

Mas assim é, diz VIDARI (Corso de Diritto Comm. tom. I, n. ${ }^{\circ}$ 97), explicando a disposição correlata do Cod. Italiano, "perché, quando vi é un'impresa cioé l'opera combinata di piú persone e di capitale, diretta a conseguire certi scopi, sia che l'impresa abbia carattere singolare o collectivo; é naturale presumere che l'imprenditore voglia appunto valersi dell'opera altrui o dei propri capitali, se non che di quelli d'altri, a scopi di lucro e di speculazione; giocché egli entende guadagnare sulla differenza che quell'opera e quei capitali gli costano e il prezzo che si fará pagare da quelli a cui prestará le cose lavorate"

Em nenhum dos casos, porem, a que a jurisprudencia tem applicado a theoria do accessorio, manifestam-se os requisitos da mercancia. Trata-se de actos que, como dizem LYON CAEN \& RENAULT, não constituem o exercicio do commercio; apenas lhe são connexos.

$\mathrm{Na}$ acquisição de vehiculos para o transporte de mercadorias, de livros para a escripta, por exemplo, evidente é a relação com a industria do adquirente; mas, onde os requisitos da mercancia com referencia a taes actos, onde a inseparabilidade que justifique a sua subordinação áquella industria, ou, siquer, a razão de interesse publico 
que determine a sua sujeição ás leis e á jurisdição do commercio?

A simples relação de finalidade não basta para a identificação de actos substancialmente differentes.

LYON CAEN \& RENAULT, elles proprios, o reconhecem quando se referem aos actos connexos ao exercicio do commercio, que têm por objecto immoveis, taes como a compra ou a locação de immoveis para um estabelecimento commercial. (Op. cit. tom. I, n. ${ }^{\circ}$ 172) $\mathrm{E}$ isso porque, dizem elles, seria illogico considerar commerciaes actos que, segundo a lei, são essencialmente civis.

A' bôa logica, porem, não nos parece menos repugnante considerar como mercancia a compra sem intenção de revenda, que a lei (Cod. francez, art. 632; Cod. brasileiro, art. 191) virtualmente declara civil.

Nem ha motivo para deduzir-se da presumpção de commercialidade estabelecida no art. 638 do Cod. Comm. francez, como pretendem os adeptos da doutrina que analysamos, que o legislador a creou em razão da dependencia ou connexão em que se deva presumir a obrigação contrahida por um commerciante com a profissão que exerce; dependencia ou connexão de que, sem duvida, resultaria a justificação da theoria do accessorio, perante a lei franceza e a de outros paizes em que vigora identica disposição.

Aquella presumpção decorre principalmente da qualidade profissional da pessôa que se obriga, não requer a prova da dependencia da obrigação com o exercicio da industria mercantil, tendo por fim derimir, na pratica, quaesquer duvidas sobre a natureza dos actos praticados por negociantes.

Não é: absoluta, não estabelece a commercialidade de pleno direito, é juris tantum, podendo ser destruida por prova em contrario, como reconhecem os proprios LYON CAEN \& Renault

Os actos commerciaes a titulo de accessorio, ao contrario, assim são considerados em razão da sua dependencia 
com o exercicio da industria mercantil, mediante a prova dessa dependencia, constituindo, portanto, uma qualificação de pleno direito.

Onde, pois, a paridade, onde a geneologia?

Encontra-se, é verdade, na jurisprudencia allemã e na italiana, commercialistas como THoLl e MARGHIERI, que fazem referencia a actos, que elles denomniam accessorios, e decorrem de identica presumpção de commercialidade estabelecida nos cods. allemão e italiano, como no francez. Mas, o fundamento legal dessa classificação é, no conceito dos citados commercialistas, a qualidade profissional de quem pratica taes actos, não a simples relação em que estejam com o exercicio dum commercio.

Assim, perante a doutrina geral do Direito, não nos parece fundada em bases solidas a theoria do accessorio, aliás, repudiada por Jousse, desde o tempo da Ordenança de 1673 , e modernamente refutada por DESJARDINS ( $R e-$ vue Critique de Leg. 1864, tomo 24, pgs. 206 e seguintes).

Perante a lei commercial brasileira, tão facil quão peremptoria é a demonstração de que é inadmissivel a qualificação de actos commerciaes a titulo de accessorios.

Em primeiro logar, não contem a lei patria disposições analogas ás dos arts 631, 632 e 638 do Cod. Comm. francez, em que se pretende fundamentar a theoria, de que tratamos. Apenas, num caso particular, o Cod. brasileiro estabelece indirectamente a presumpção de commercialidade com fundamento na qualidade de commerciante do devedor, dispondo, no art. 426, que as notas promissorias e escriptos particulares, sendo assignados por commerciantes, serão reputados como letras da terra.

Em regra, porem, conforme o systema da nossa legislação, a qualidade das partes é, de per si, sem influencia para a sua sujeição ás leis e á competencia jurisdicional do 
commercio. Mesmo quando ambas as partes são commerciantes, diz o art. 11 do reg. 737 de 1850, é essencial que a divida seja tambem commercial.

Méramente demonstrativa, embóra, a enumeração das especies consideradas mercancia no art. 19 do cit. reg. 737, não é menos certo, de cutra parte, que ás leis commerciaes só podem ser sujeitas, em falta de expressa disposição, os actos em que se verificam os caracteres da mercancia.

A razão de utilidade social, que justifica a derogação dos principios e a contravenção á natureza das coisas, relativamente á commercialidade attribuida por lei a certos actos essencialmente civis, não é da alçada do interprete, nem se sujeita ás ampliações dos tribunaes - Quod contra rationem juris receptum est, non debet produci ad consequentias. (Digesto, frg. 141 "de regulis juris")

Emprehendendo este ensaio de critica, o interesse e a novidade do assumpto sobrepujaram o sentimento da nossa incompetencia. Quizemos apenas provocar o estudo dos mais habilitados para a elucidação de questões frequentemente sujeitas ás deliberações dos juizes e tribunaes e para cuja solução não conhecemos na jurisprudencia patria subsidios a que pudessemos recorrer.

Valha-nos isso de excusa, perante os nossos mestres, para os erros e imperfeições em que tenhamos incidido"

1922

GabRIEL DE REZENDE. 